\title{
Characterization of Active Sites on Carbon Catalysts
}

\author{
José L. Figueiredo, Manuel F. R. Pereira, Maria M. A. Freitas, and José J. M. Órfão
}

A method based on the deconvolution of TPD spectra is proposed for the characterization of surface oxygen groups, which can act as the active sites on carbon catalysts. The method, which was previously used to characterize activated carbons oxidized in the gas phase, has been extended and applied to other materials, carbons oxidized in the liquid phase. It is shown that this method fits quite well the TPD experimental data of the original activated carbon as well as the gas-phase and liquid-phase oxidized materials and is suitable to estimate the amounts of each type of oxygen surface groups.

\section{Introduction}

Carbon materials are finding an increasing number of applications in catalysis, either as supports or as catalysts on their own. The success of these applications results from the specific properties of these materials, from the possibility of tailoring both their pore structure and their surface chemistry to meet the demands of the catalytic reaction envisaged. ${ }^{1}$

The nature and concentration of functional groups on the surface of the carbon material is particularly relevant, as such groups can act as anchoring sites for the active phases, or their precursors, in the preparation of supported catalysts, or they can be the active sites for specific catalytic reactions. Oxygen functional groups are most important in this context, as they can be formed spontaneously by exposure to the atmosphere; in addition, the concentration of such groups can be further modified by oxidative and thermal treatments. ${ }^{2}$

Thus, it has been shown that homogeneous catalysts consisting of transition metal complexes can be anchored onto the surface of carbon materials by chemical bonding of functionalized ligands with oxygen functional groups on the carbon surface $^{3,4}$ or by direct coordination of these to the metal center. ${ }^{5}$ Similar methodologies were used to prepare well-dispersed and stable carbon-supported metal catalysts, both by impregnation ${ }^{6-8}$ and by CVD. ${ }^{9}$

The same approach can be used to improve the performance of carbon-coated monoliths, a topic which is being developed by the group of Jacob Moulijn. ${ }^{10,11}$ Thus, in a recent report on the use of carbon-coated monoliths as supports for the immobilization of biocatalysts, it was shown that larger amounts of enzyme could be loaded upon an oxidation treatment, which increased the amounts of surface oxygen groups. ${ }^{12}$ Clearly, the surface chemistry of the material must be modified according to the nature of the enzyme, to optimize such structured catalysts.

On the other hand, the decisive role of surface chemistry on the catalytic properties of carbon materials, which was recognized long ago, ${ }^{13}$ could only be quantitatively established recently, when suitable methods of analysis of the carbon surface groups became available. For instance, it has been shown that carbonyl/quinone groups are the active sites for the oxidative dehydrogenation of ethylbenzene to styrene, and a linear correlation between the activity of carbon catalysts and the concentration of such sites was established. ${ }^{14}$ Similarly, the catalytic activity of carbon materials for the dehydration of methanol to dimethyl ether was correlated with the concentration of strong acid sites. ${ }^{15}$

Different techniques are available to characterize these materials, such as TPD, XPS, FTIR, and chemical or electrochemical titration methods. ${ }^{16}$ Nevertheless, none of these methods allows a straightforward quantitative analysis of the surface functional groups.

XPS is a surface technique that only gives an estimate of the chemical composition of the uppermost surface layers (about $10-15 \mathrm{~nm}$ in depth), which makes this technique ideal for surface analysis, for carbon fibers and graphites. When applied to porous carbons for the determination of the oxygen surface groups, XPS has the following drawbacks: (i) the external surface area is only a small fraction of the total surface area and it is not representative of all of the material; (ii) the holes in the surface can affect the final results because the surface is not flat; (iii) the analysis is made in high-vacuum, that is, under conditions quite different from those usually used in the applications of the carbon catalyst, and a rearrangement of the surface can occur; and (iv) deconvolution of the $\mathrm{O} 1 \mathrm{~s}$ and $\mathrm{C} 1 \mathrm{~s}$ peaks is not straightforward, and it is still a matter of discussion.

FTIR is mainly used as a qualitative technique for the evaluation of the chemical structure of carbon materials. It is not easy to get good spectra because carbons are black materials that absorb almost all of the radiation in the visible spectrum, and the peaks obtained are usually a sum of the interactions of different types of groups. ${ }^{17}$

Chemical analyses, such as the traditional Boehm titration method, ${ }^{18}$ present several drawbacks, such as: the equilibrium times are very long for microporous materials; there are problems of reproducibility when dealing with small amounts of sample; and this technique only can determine about $50 \%$ of the total oxygen available in activated carbons. ${ }^{19}$

TPD is a thermal analysis method that is becoming more popular for the characterization of the oxygen-containing groups of activated carbons. In this technique, all of the surface groups are thermally decomposed releasing $\mathrm{CO}$ and/or $\mathrm{CO}_{2}$ and in some cases $\mathrm{H}_{2} \mathrm{O}$ and $\mathrm{H}_{2}$, at different temperatures. The nature of the groups can be assessed by the decomposition temperature and 
Table 1. Textural Properties of Selected Materials

\begin{tabular}{lccccc}
\hline sample & $\begin{array}{c}V_{\text {micro }} \\
\mathrm{cm}^{3} \mathrm{~g}^{-1}\end{array}$ & $\begin{array}{c}S_{\text {meso }} \\
\mathrm{m}^{2} \mathrm{~g}^{-1}\end{array}$ & $\begin{array}{c}W_{01} \\
\mathrm{~cm}^{3} \mathrm{~g}^{-1}\end{array}$ & $\begin{array}{c}W_{02} \\
\mathrm{~cm}^{3} \mathrm{~g}^{-1}\end{array}$ & $\begin{array}{c}L \\
\mathrm{~nm}\end{array}$ \\
\hline $\mathrm{S}$ & 0.445 & 36 & 0.418 & 0.030 & 0.86 \\
$\mathrm{~S}_{\mathrm{O}_{2}, 3 \mathrm{~h}}$ & 0.447 & 69 & 0.395 & 0.075 & 1.2 \\
$\mathrm{~S}_{\mathrm{O}_{2}, 10 \mathrm{~h}}$ & 0.504 & 124 & 0.403 & 0.118 & 1.5 \\
$\mathrm{~S}_{\mathrm{N}_{2} \mathrm{O}, 10 \mathrm{~h}}$ & 0.508 & 28 & 0.494 & 0.096 & 1.2 \\
$\mathrm{~S}_{\mathrm{HNO}_{3}, 6 \mathrm{~h}}$ & 0.410 & 47 & 0.380 & 0.032 & 0.85
\end{tabular}

type of gas released, and their respective amounts by the areas of the peaks. ${ }^{2}$ In this technique, all of the oxygen present is released and determined as $\mathrm{CO}, \mathrm{CO}_{2}$, and $\mathrm{H}_{2} \mathrm{O}$, as confirmed by comparing the oxygen obtained by TPD and by elemental analysis. $^{2}$ The major problem is the difficulty in identifying each surface group individually, because TPD spectra show composite $\mathrm{CO}$ and $\mathrm{CO}_{2}$ peaks. In a previous work, ${ }^{2}$ we presented a simplified method to deconvolute the TPD spectra to estimate the amount of each type of oxygen surface group for activated carbons oxidized in the gas phase. In this work, an extension of the previous method is proposed and applied not only to other gas-phase oxidized samples but also to liquid-phase oxidized materials. In our opinion, this method is suitable to estimate the type and amount of each surface group in a simple and easy way, and can be applied to all carbon catalysts.

\section{Experimental Section}

An activated carbon was prepared from a coconut shell char by activation with $\mathrm{H}_{2} \mathrm{O}$ at $1173 \mathrm{~K}$. It was subsequently oxidized in the gas phase, with $5 \% \mathrm{O}_{2}\left(\right.$ in $\mathrm{N}_{2}$ ) at $698 \mathrm{~K}$ or with $50 \%$ $\mathrm{N}_{2} \mathrm{O}$ (in $\mathrm{N}_{2}$ ) for different times, to achieve the desired burnoff (B.O.), and in the liquid phase, with $5 \mathrm{M}$ nitric acid at the boiling temperature in a Soxhlet for different times. The materials oxidized in the liquid phase were subsequently washed with distilled water until neutral $\mathrm{pH}$, and dried in an oven at $383 \mathrm{~K}$ for $24 \mathrm{~h}$. Thus, the following samples were prepared: $\mathrm{S}$, original carbon; $\mathrm{S}_{\mathrm{O}_{2}, 3 \mathrm{~h}}$, $\mathrm{S}$ oxidized with $5 \% \mathrm{O}_{2}$ for $3 \mathrm{~h}$ at $698 \mathrm{~K}$ (B.O. = $12 \%) ; \mathrm{S}_{\mathrm{O}_{2}, 6 \mathrm{~h}}, \mathrm{~S}$ oxidized with $5 \% \mathrm{O}_{2}$ for $6 \mathrm{~h}$ at $698 \mathrm{~K}$ (B.O. $=$ $19 \%) ; \mathrm{S}_{\mathrm{O}_{2}, 10 \mathrm{~h}}$, $\mathrm{S}$ oxidized with $5 \% \mathrm{O}_{2}$ for $10 \mathrm{~h}$ at $698 \mathrm{~K}$ (B.O. $=42 \%) ; \mathrm{S}_{\mathrm{N}_{2} \mathrm{O}, 3 \mathrm{~h}}, \mathrm{~S}$ oxidized with $50 \% \mathrm{~N}_{2} \mathrm{O}$ for $3 \mathrm{~h}$ at $773 \mathrm{~K}$

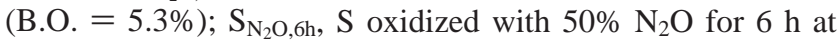
$773 \mathrm{~K}($ B.O. $=14 \%) ; \mathrm{S}_{\mathrm{N}_{2} \mathrm{O}, 10 \mathrm{~h}}, \mathrm{~S}$ oxidized with $50 \% \mathrm{~N}_{2} \mathrm{O}$ for $10 \mathrm{~h}$ at $773 \mathrm{~K}($ B.O. $=30 \%) ; \mathrm{S}_{\mathrm{HNO}_{3}, 3 \mathrm{~h}}, \mathrm{~S}$ oxidized with $5 \mathrm{M}$ nitric acid for $3 \mathrm{~h}$ at boiling temperature; and $\mathrm{S}_{\mathrm{HNO}_{3}, 6 \mathrm{~h}}, \mathrm{~S}$ oxidized with $5 \mathrm{M}$ nitric acid for $6 \mathrm{~h}$ at boiling temperature.

The textural characterization of the materials was based on the $\mathrm{N}_{2}$ adsorption isotherms, determined at $77 \mathrm{~K}$ with a Coulter Omnisorp 100 CX apparatus. BET surface areas were calculated, as well as the micropore volumes $\left(V_{\text {micro }}\right)$ and mesopore surface areas $\left(S_{\text {meso }}\right)$ according to the $t$-method. The adsorption data were also analyzed with the Dubinin equation. When a type IV deviation occurred, two microporous structures were taken into account, and the corresponding volumes, $W_{01}$ and $W_{02}$, were calculated. The Stoeckli equation was used to estimate the average micropore width of the smaller pores $(L)$.

The TPD profiles were obtained with a custom built setup, consisting of a U-shaped tubular microreactor, placed inside an electrical furnace. The mass flow rate of the helium carrier gas $(69 \mu \mathrm{g} / \mathrm{s})$ and the heating rate of the furnace $(5 \mathrm{~K} / \mathrm{min})$ were controlled with appropriate units. The amounts of $\mathrm{CO}$ and $\mathrm{CO}_{2}$ desorbed from the carbon samples $(0.1 \mathrm{~g})$ were monitored with a SPECTRAMASS Dataquad quadrupole mass spectrometer.

\section{Results and Discussion}

3.1. Textural Characterization. Table 1 shows the textural properties of selected samples. It may be observed that gas- a)

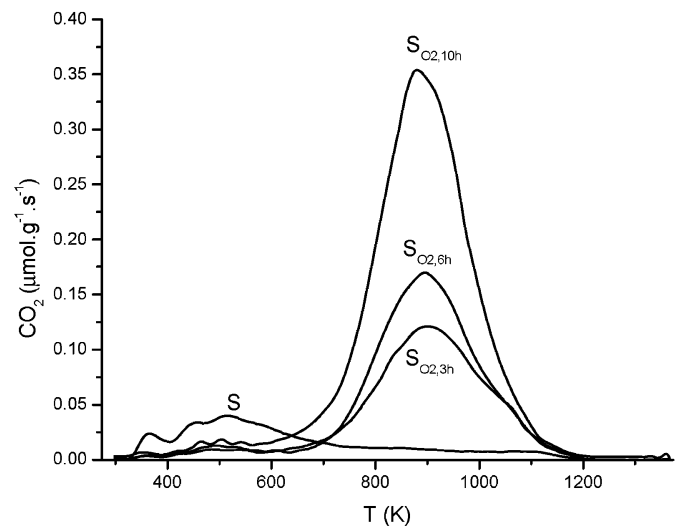

b)

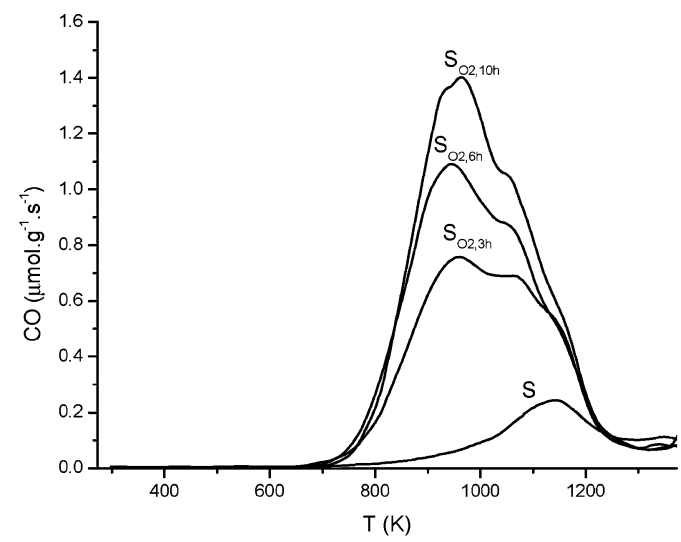

Figure 1. TPD spectra for the samples oxidized in $5 \% \mathrm{O}_{2}$ in $\mathrm{N}_{2}$ : (a) $\mathrm{CO}_{2}$ evolution; (b) $\mathrm{CO}$ evolution.

a)

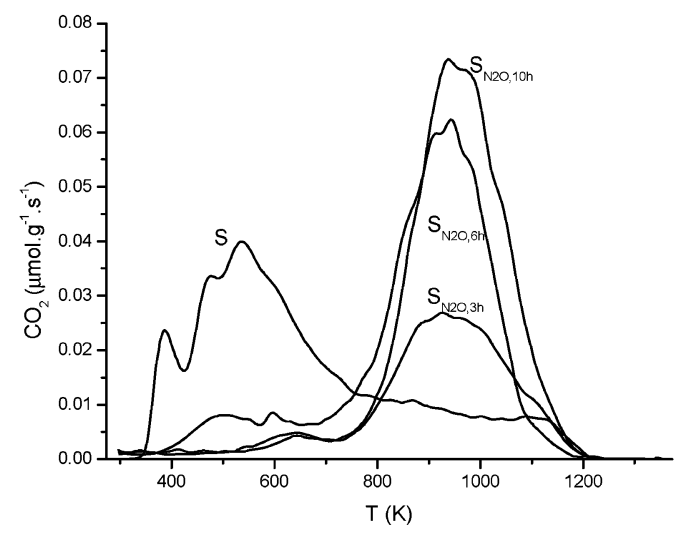

b)

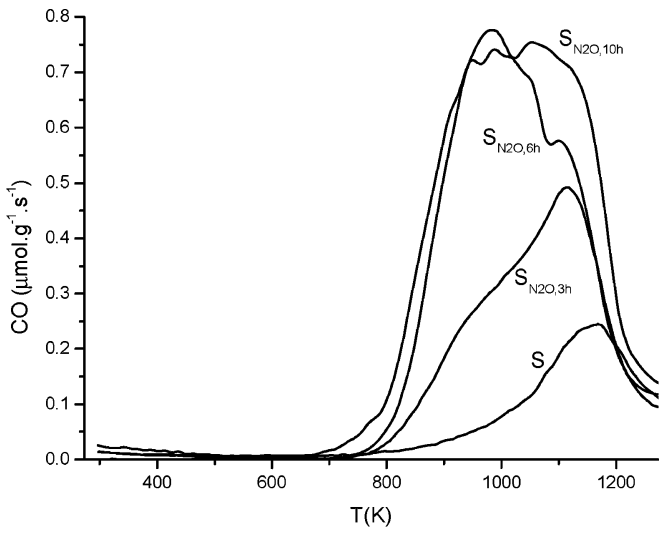

Figure 2. TPD spectra for the samples oxidized in $50 \% \mathrm{~N}_{2} \mathrm{O}$ in $\mathrm{N}_{2}$ : (a) $\mathrm{CO}_{2}$ evolution; (b) $\mathrm{CO}$ evolution. 
a)

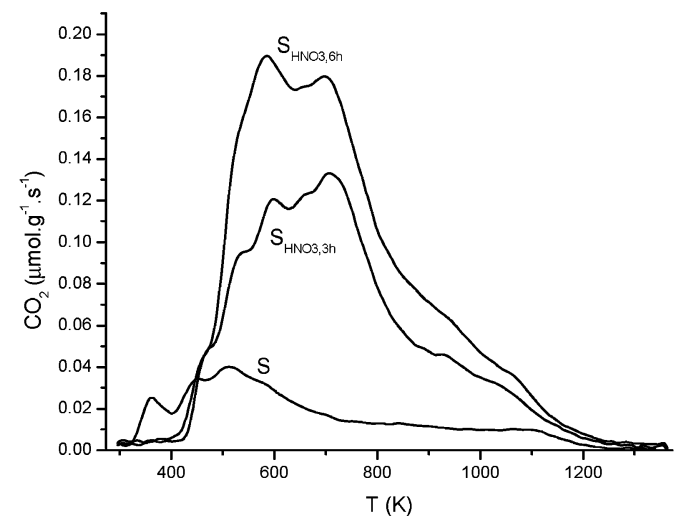

b)

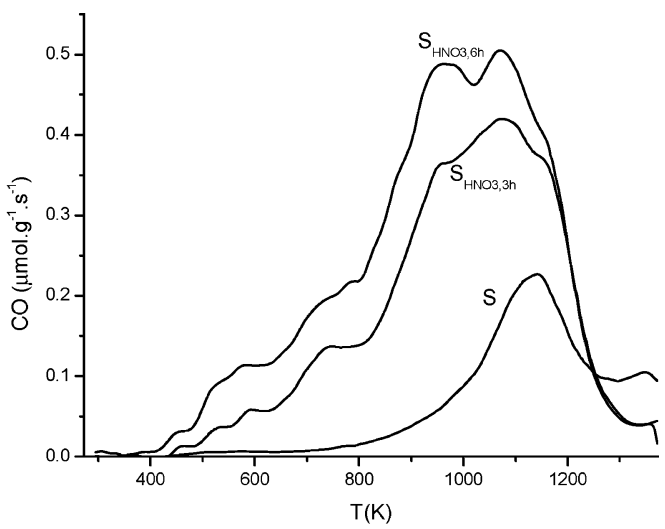

Figure 3. TPD spectra for the samples oxidized with $\mathrm{HNO}_{3} 5 \mathrm{M}$ : (a) $\mathrm{CO}_{2}$ evolution; (b) $\mathrm{CO}$ evolution.

a)

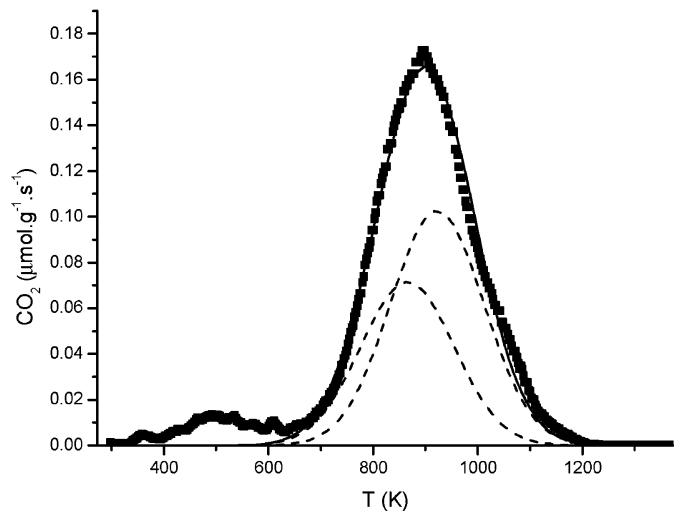

b)

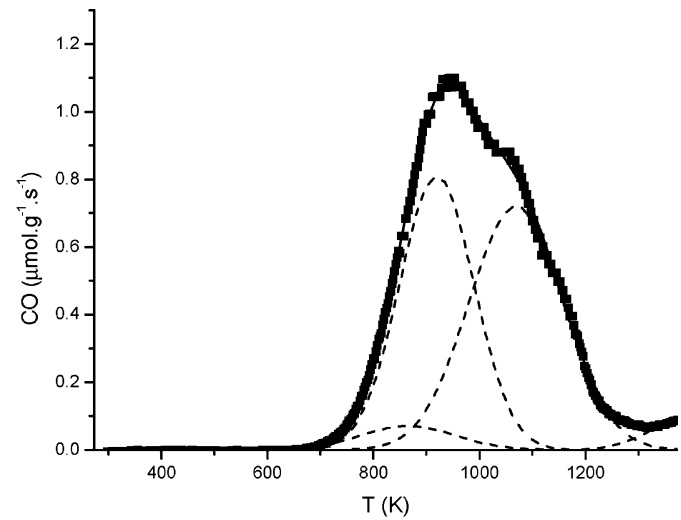

Figure 4. Deconvolution of TPD spectra for the sample $\mathrm{S}_{\mathrm{O}_{2}, 6 \mathrm{~h}}$ : (a) $\mathrm{CO}_{2}$ spectrum; (b) $\mathrm{CO}$ spectrum (匹, TPD experimental data; - - -, individual peaks; -sum of the individual peaks).

a)

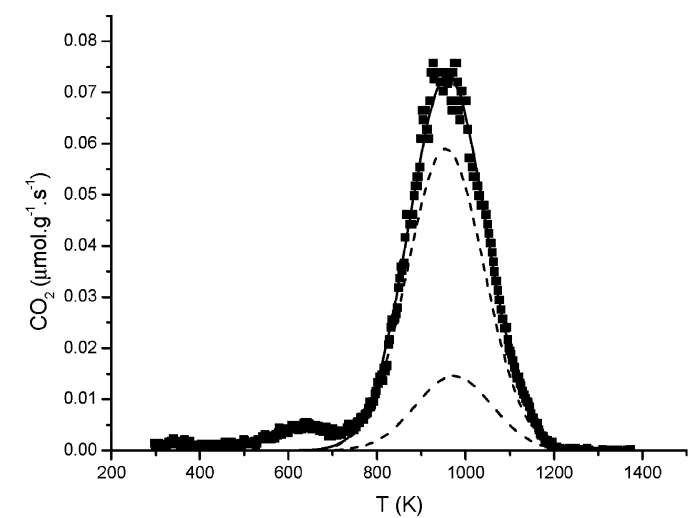

b)

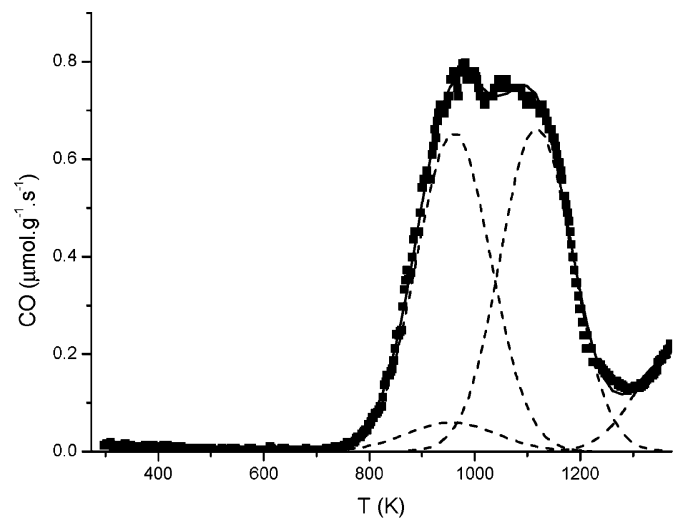

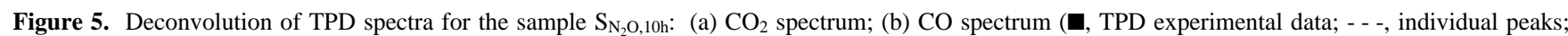
- , sum of the individual peaks).

phase oxidations increase the micropore volume, the mesopore surface area, and the average micropore width $\left(\mathrm{S}_{\mathrm{O}_{2}, 3 \mathrm{~h}}, \mathrm{~S}_{\mathrm{O}_{2}, 6 \mathrm{~h}}\right.$, and $\mathrm{S}_{\mathrm{O}_{2}, 10 \mathrm{~h}}$ vs $\mathrm{S}$ ), with the exception of the $\mathrm{N}_{2} \mathrm{O}$ oxidation that slightly decreases the mesopore surface area. Liquid-phase oxidation has no significant impact on the textural properties

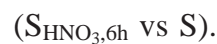

3.2. Surface Chemistry Characterization. The surface chemistry was evaluated using different techniques: elemental analysis, FTIR, XPS, chemical titrations (Boehm's method), and TPD. The results of the first four techniques are not shown here, but in all cases an increase in the oxygen content with the extent of the oxidation treatment was observed. In this work, only TPD results are analyzed in detail. Figures $1-3$ show the TPD results for the oxidized samples considered in this work. It can be observed that gas-phase oxidations (Figures 1 and 2) increase mainly the $\mathrm{CO}$ releasing groups at around $950 \mathrm{~K}$ (phenol groups) and $1100 \mathrm{~K}$ (carbonyl/quinone groups) and $\mathrm{CO}_{2}$ releasing groups at around $850 \mathrm{~K}$ (carboxyl anhydride groups) and $950 \mathrm{~K}$ (lactone groups). In these samples, no carboxylic acid groups are present, because they decompose at temperatures below those used for the oxidation. Liquid-phase treatments (Figure 3) have the particularity to increase the carboxylic groups, which are released as $\mathrm{CO}_{2}$ at low temperatures (below $800 \mathrm{~K}$ ).

3.3. Deconvolution of TPD Spectra. To determine the amount of each surface group, the deconvolution of the $\mathrm{CO}$ and $\mathrm{CO}_{2}$ TPD spectra was carried out. A multiple Gaussian function was used for fitting each of the TPD spectra, taking the position of the peak center as the initial estimate. The numerical calculations were based on a nonlinear routine, which minimized the square of the deviations, using the LevenbergMarquardt method to perform the iterations. The use of Gaussian functions is justified by the shape of the TPD peaks, which are a result of a continuous random distribution of binding energies 
a)

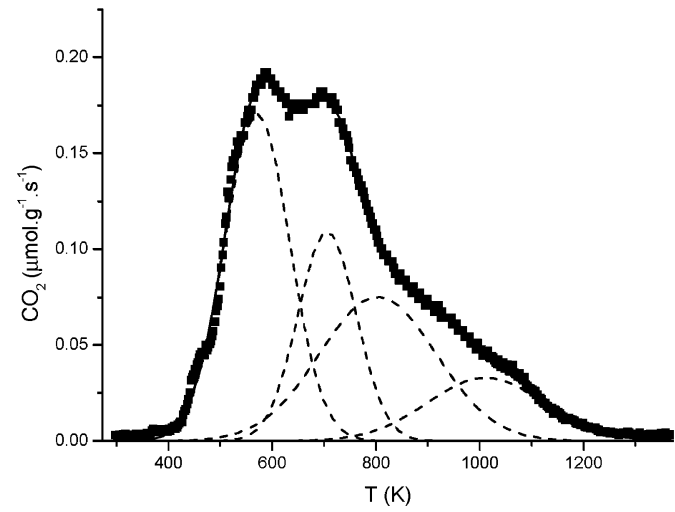

b)

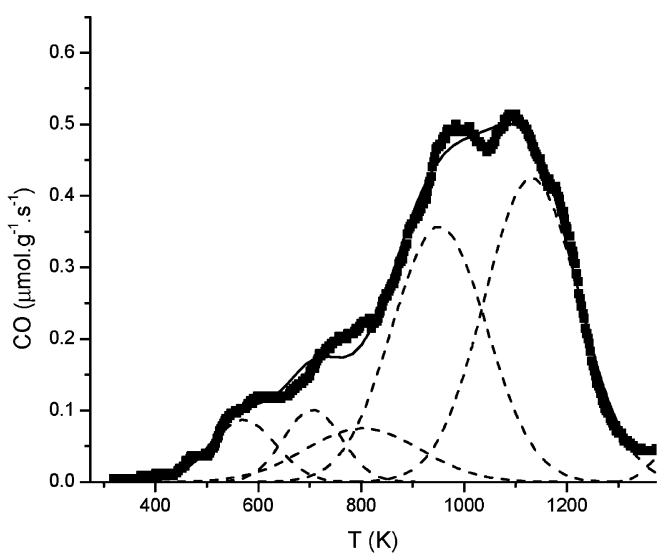

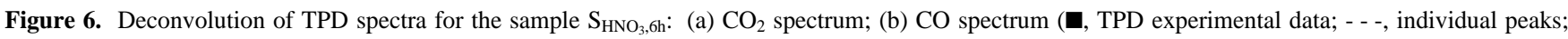
- , sum of the individual peaks).

Table 2. Results of the Deconvolution of $\mathrm{CO}_{2}$ TPD Spectra Using a Multiple Gaussian Function

\begin{tabular}{|c|c|c|c|c|c|c|c|c|c|c|c|c|}
\hline \multirow[b]{2}{*}{ sample } & \multicolumn{3}{|c|}{ peak \#1 } & \multicolumn{3}{|c|}{ peak \#2 } & \multicolumn{3}{|c|}{ peak \#3 } & \multicolumn{3}{|c|}{ peak \#4 } \\
\hline & $\begin{array}{l}T_{\mathrm{M}} \\
(\mathrm{K})\end{array}$ & $\begin{array}{l}W \\
(\mathrm{~K})\end{array}$ & $\begin{array}{c}A \\
\left(\mu \mathrm{mol} \mathrm{g}^{-1}\right)\end{array}$ & $\begin{array}{l}T_{\mathrm{M}} \\
(\mathrm{K})\end{array}$ & $\begin{array}{l}W \\
(\mathrm{~K})\end{array}$ & $\begin{array}{c}A \\
\left(\mu \mathrm{mol} \mathrm{g}{ }^{-1}\right)\end{array}$ & $\begin{array}{l}T_{\mathrm{M}} \\
(\mathrm{K})\end{array}$ & $\begin{array}{l}W \\
(\mathrm{~K})\end{array}$ & $\begin{array}{c}A \\
\left(\mu \mathrm{mol} \mathrm{g}^{-1}\right)\end{array}$ & $\begin{array}{l}T_{\mathrm{M}} \\
(\mathrm{K})\end{array}$ & $\begin{array}{l}W \\
(\mathrm{~K})\end{array}$ & $\begin{array}{c}A \\
\left(\mu \mathrm{mol} \mathrm{g}{ }^{-1}\right)\end{array}$ \\
\hline$S$ & 511 & 157 & 81.2 & 650 & 206 & 54.7 & 884 & 173 & 28.9 & 1095 & 173 & 23.9 \\
\hline $\mathrm{S}_{\mathrm{O}_{2}, 3 \mathrm{~h}}$ & & & & & & & 885 & 209 & 107 & 917 & 209 & 268 \\
\hline $\mathrm{S}_{\mathrm{O}_{2}, 6 \mathrm{~h}}$ & & & & & & & 886 & 178 & 192 & 922 & 178 & 275 \\
\hline $\mathrm{S}_{\mathrm{O}_{2}, 10 \mathrm{~h}}$ & & & & & & & 876 & 174 & 540 & 904 & 174 & 373 \\
\hline $\mathrm{S}_{\mathrm{N}_{2} \mathrm{O}, 3 \mathrm{~h}}$ & & & & & & & 940 & 219 & 73.2 & 970 & 219 & 16.8 \\
\hline $\mathrm{S}_{\mathrm{N}_{2} \mathrm{O}, 6 \mathrm{~h}}$ & & & & & & & 919 & 168 & 128 & 975 & 168 & 32.4 \\
\hline $\mathrm{S}_{\mathrm{N}_{2} \mathrm{O}, 10 \mathrm{~h}}$ & & & & & & & 955 & 172 & 152 & 973 & 172 & 374 \\
\hline $\mathrm{S}_{\mathrm{HNO}_{3}, 3 \mathrm{~h}}$ & 571 & 149 & 228 & 716 & 123 & 166 & 822 & 228 & 131 & 1005 & 228 & 86.5 \\
\hline $\mathrm{S}_{\mathrm{HNO}_{3}, 6 \mathrm{~h}}$ & 571 & 125 & 322 & 706 & 112 & 184 & 803 & 224 & 253 & 1012 & 224 & 111 \\
\hline
\end{tabular}

Table 3. Results of the Deconvolution of CO TPD Spectra Using a Multiple Gaussian Function

\begin{tabular}{|c|c|c|c|c|c|c|c|c|c|c|c|c|c|c|c|}
\hline \multirow[b]{2}{*}{ sample } & \multicolumn{3}{|c|}{ peak \#1 } & \multicolumn{3}{|c|}{ peak \#2 } & \multicolumn{3}{|c|}{ peak \#3 } & \multicolumn{3}{|c|}{ peak \#4 } & \multicolumn{3}{|c|}{ peak \#5 } \\
\hline & $\begin{array}{l}T_{\mathrm{M}} \\
(\mathrm{K})\end{array}$ & $\begin{array}{l}W \\
(\mathrm{~K})\end{array}$ & $\begin{array}{c}A \\
\left(\mu \mathrm{mol} \mathrm{g}^{-1}\right)\end{array}$ & $\begin{array}{l}T_{\mathrm{M}} \\
(\mathrm{K})\end{array}$ & $\begin{array}{l}W \\
(\mathrm{~K})\end{array}$ & $\begin{array}{c}A \\
\left(\mu \mathrm{mol} \mathrm{g}{ }^{-1}\right)\end{array}$ & $\begin{array}{l}T_{\mathrm{M}} \\
(\mathrm{K})\end{array}$ & $\begin{array}{l}W \\
(\mathrm{~K})\end{array}$ & $\begin{array}{c}A \\
\left(\mu \mathrm{mol} \mathrm{g}{ }^{-1}\right)\end{array}$ & $\begin{array}{l}T_{\mathrm{M}} \\
(\mathrm{K})\end{array}$ & $\begin{array}{l}W \\
(\mathrm{~K})\end{array}$ & $\begin{array}{c}A \\
\left(\mu \mathrm{mol} \mathrm{g}^{-1}\right)\end{array}$ & $\begin{array}{l}T_{\mathrm{M}} \\
(\mathrm{K})\end{array}$ & $\begin{array}{l}W \\
(\mathrm{~K})\end{array}$ & $\begin{array}{c}A \\
\left(\mu \mathrm{mol} \mathrm{g}{ }^{-1}\right)\end{array}$ \\
\hline$S$ & 511 & 157 & 0.4 & 650 & 206 & 22.0 & 884 & 173 & 28.9 & 998 & 146 & 103 & 1158 & 146 & 474 \\
\hline $\mathrm{S}_{\mathrm{O}_{2}, 3 \mathrm{~h}}$ & & & & & & & 885 & 209 & 107 & 939 & 154 & 1548 & 1105 & 154 & 1272 \\
\hline $\mathrm{S}_{\mathrm{O}_{2}, 6 \mathrm{~h}}$ & & & & & & & 886 & 178 & 192 & 933 & 154 & 2184 & 1091 & 154 & 1452 \\
\hline $\mathrm{S}_{\mathrm{O}_{2}, 10 \mathrm{~h}}$ & & & & & & & 876 & 174 & 540 & 947 & 140 & 2484 & 1094 & 140 & 1500 \\
\hline $\mathrm{S}_{\mathrm{N}_{2} \mathrm{O}, 3 \mathrm{~h}}$ & & & & & & & 940 & 219 & 73.2 & 957 & 138 & 470 & 1116 & 138 & 940 \\
\hline $\mathrm{S}_{\mathrm{N}_{2} \mathrm{O}, 6 \mathrm{~h}}$ & & & & & & & 919 & 168 & 128 & 945 & 156 & 1356 & 1096 & 156 & 1178 \\
\hline $\mathrm{S}_{\mathrm{N}_{2} \mathrm{O}, 10 \mathrm{~h}}$ & & & & & & & 955 & 172 & 152 & 959 & 138 & 1356 & 1116 & 138 & 1392 \\
\hline $\mathrm{S}_{\mathrm{HNO}_{3}, 3 \mathrm{~h}}$ & 571 & 149 & 73.2 & 716 & 123 & 157 & 822 & 228 & 131 & 957 & 172 & 780 & 1128 & 172 & 892 \\
\hline $\mathrm{S}_{\mathrm{HNO}_{3}, 6 \mathrm{~h}}$ & 571 & 125 & 164 & 706 & 112 & 170 & 803 & 224 & 253 & 952 & 183 & 985 & 1132 & 183 & 1172 \\
\hline
\end{tabular}

of the surface groups. ${ }^{20}$ For the gas-phase oxidized samples, the assumptions made and justified in a previous work ${ }^{2}$ were followed:

(a) The $\mathrm{CO}_{2}$ spectra are decomposed into two contributions, corresponding to carboxylic anhydrides $\left(\mathrm{CO}_{2}\right.$ peak \#3) and lactones $\left(\mathrm{CO}_{2}\right.$ peak \#4). There is not any low-temperature $\mathrm{CO}_{2}$ evolution, because these samples were processed at a temperature higher than the decomposition of carboxylic acids.

(b) The carboxylic anhydrides decompose by releasing one $\mathrm{CO}$ and one $\mathrm{CO}_{2}$ molecule. Thus, for samples oxidized in the gas phase, the first component in the $\mathrm{CO}$ spectrum corresponds to the carboxylic anhydrides, with a peak of the same shape as and equal magnitude to the $\mathrm{CO}_{2}$ peak \#3 (CO peak \#3). This peak is pre-defined from the deconvolution of the $\mathrm{CO}_{2}$ spectra.

(c) In addition to the carboxylic anhydrides ( $\mathrm{CO}$ peak \#3), the $\mathrm{CO}$ spectrum includes contributions from phenols ( $\mathrm{CO}$ peak \#4) and carbonyl/quinones (CO peak \#5).

(d) It is assumed that secondary reactions at high temperatures are negligible.

(e) In the $\mathrm{CO}_{2}$ spectrum, the width at half-height was taken the same for both peaks.

Two additional assumptions were made in the present work: (f) A new $\mathrm{CO}$ peak around $1370 \mathrm{~K}$ was included (CO peak \#6). This results from the observation that the $\mathrm{CO}$ spectrum does not return to the baseline at high temperatures, and it seems that a new peak is being formed at those temperatures. This peak can be assigned to basic groups, such as pyrones and chromenes, ${ }^{21}$ or may result from the rearrangement of the surface because temperatures are higher than those used in the preparation of these samples. This peak was used for the deconvolution, but it was not taken into consideration for quantitative analysis.

(g) The same width at half-height was considered for the phenol and carbonyl groups. This was necessary mainly in the case of samples where there were no peak shoulders.

To use this method to fit also the TPD spectra of activated carbons oxidized in the liquid phase, the following assumptions were necessary:

(h) There are two types of carboxylic groups, which can be assigned to strongly acidic $\left(\mathrm{CO}_{2}\right.$ peak \#1) and less acidic $\left(\mathrm{CO}_{2}\right.$ peak \#2) carboxylic groups. ${ }^{21}$

(i) The CO spectra of these samples present shoulders at low temperatures that cannot be justified by the carboxylic anhydride groups. These shoulders appear in the same region of the decomposition of the carboxylic groups. In the literature, it is 
always assumed that these groups decompose releasing only $\mathrm{CO}_{2}$. Our results show that some $\mathrm{CO}$ is formed at the same time. The release of $\mathrm{CO}$ at similar temperatures can be observed in the literature for several TPD's spectra from $\mathrm{HNO}_{3}$ oxidized carbons. ${ }^{2-24}$ A possible justification could be related to the fact that when $\mathrm{CO}_{2}$ molecules are released in the micropores, they are always in the proximity of the surfaces, and thus there is a high probability of interaction with unoccupied active sites just formed by the decomposition of other carboxylic groups originating another surface complex $(\mathrm{C}[\mathrm{O}])$ and a free $\mathrm{CO} .{ }^{25}$ To verify the validity of this explanation, two additional TPD experiments were carried out. In the first one, the TPD experiment was stopped at $573 \mathrm{~K}$, and several $\mathrm{CO}_{2}$ pulses were introduced at this temperature. There was no $\mathrm{CO}$ formation, meaning that the previous justification does not apply to the present situation. In addition, the TPD at high temperatures of the sample previously submitted to the $\mathrm{CO}_{2}$ pulses is coincident with the TPD of the original sample, showing that no new oxygen surface groups releasing $\mathrm{CO}$ at high temperatures were formed. In the second experiment, a flow of $\mathrm{CO}_{2}$ was introduced at $573 \mathrm{~K}$ during $1 \mathrm{~h}$ in a sample previously submitted to a thermal treatment up to $1373 \mathrm{~K}$ in He flow (the equivalent of a TPD experiment). Afterward, a new TPD of this sample was carried out, which showed a TPD profile coincident with the original sample previously treated at $1373 \mathrm{~K}$. This result shows that no oxygen surface groups are introduced when $\mathrm{CO}_{2}$ contact with an activated carbon sample at $573 \mathrm{~K}$. These two experiments show that $\mathrm{CO}$ is not released as a secondary reaction when the carboxylic acid groups are decomposed releasing $\mathrm{CO}_{2}$. Nevertheless, as it was observed experimentally that these small $\mathrm{CO}$ peaks at low temperatures are released at the same time as the $\mathrm{CO}_{2}$ peaks, it was assumed that for activated carbons oxidized in the liquid phase there are two $\mathrm{CO}$ peaks at low temperature ( $\mathrm{CO}$ peaks \#1 and \#2) with the same peak center and width at half-height of those obtained for the carboxylic groups in the $\mathrm{CO}_{2}$ peak. Almost all of the authors ignore the $\mathrm{CO}$ peaks at low temperature, but according to Moreno-Castilla et al., ${ }^{26}$ based on the work of Surygala et al., ${ }^{27}$ the CO peak that appears at low temperatures probably comes from the decomposition of carbonyl groups in $\alpha$-substituted ketones and aldehydes.

Figures 4-6 show examples of the deconvolutions obtained with the activated carbons oxidized with $\mathrm{O}_{2}, \mathrm{~N}_{2} \mathrm{O}$, and $\mathrm{HNO}_{3}$, respectively, which fit the data quite well, both for $\mathrm{CO}$ and for $\mathrm{CO}_{2}$.

Tables 2 and 3 show the results obtained, where $T_{\mathrm{M}}$ is the temperature of the peak maximum, $W$ is the width of the peak at half-height, and $A$ is the integrated peak area. It can be observed that all of the fits give approximately the same values of $T_{\mathrm{M}}$ and $W$ for each component, when applied to the original activated carbon or to the modified carbons containing quite different types and amounts of surface groups.

Thus, the peak maxima found were between 510 and $570 \mathrm{~K}$ for the strongly acidic carboxylic groups, 650 and $720 \mathrm{~K}$ for the less acidic carboxylic groups, 800 and $900 \mathrm{~K}$ for anhydrides, 900 and $1000 \mathrm{~K}$ for lactones, 940 and $990 \mathrm{~K}$ for phenols, and 1090 and $1150 \mathrm{~K}$ for carbonyls/quinones.

\section{Conclusions}

In this work, a series of activated carbons with different surface chemistries was prepared and characterized. A new method to deconvolute the TPD spectra, using multiple Gaussian functions, was applied to estimate the amount of each type of oxygen surface group. This method proved to fit quite well the experimental data of nontreated, gas-phase oxidized and liquidphase oxidized activated carbons, with different types and amounts of each oxygen surface group. This deconvolution method is easy to use and can be applied to characterize the active sites of carbon catalysts.

\section{Acknowledgment}

This work was carried out with support from Fundação para a Ciência e a Tecnologia (FCT, Portugal) and POCI 2010, with coparticipation from FEDER, Project POCI/EQU/57369/2004 "Nanostructured carbon catalysts". Laboratório de Catálise e Materiais (LCM) is a research unit of Laboratório Associado LSRE-LCM.

\section{Literature Cited}

(1) Rodríguez-Reinoso, F. The role of carbon materials in heterogeneous catalysis. Carbon 1998, 36, 159-175.

(2) Figueiredo, J. L.; Pereira, M. F. R.; Freitas, M. M. A.; Órfão, J. J. M. Modification of the surface chemistry of activated carbons. Carbon 1999, 37, 1379-1389.

(3) Silva, A. R.; Vital, J.; Figueiredo, J. L.; Freire, C.; de Castro, B. Activated carbons with immobilised manganese(III) salen complexes as heterogeneous catalysts in the epoxidation of olefins: influence of support and ligand functionalisation on selectivity and reusability. New J. Chem. 2003, 27, 1511-1517.

(4) Silva, A. R.; Martins, M.; Freitas, M. M. A.; Figueiredo, J. L.; Freire, C.; de Castro, B. Anchoring of copper(II) acetylacetonate onto an activated carbon functionalised with a triamine. Eur. J. Inorg. Chem. 2004, 20272035.

(5) Silva, A. R.; Budarin, V.; Clark, J. H.; de Castro, B.; Freire, C. Chiral manganese(III) Schiff base complexes anchored onto activated carbon as enantio selective heterogeneous catalysts for alkene epoxidation. Carbon 2005, 43, 2096-2105.

(6) Aksoylu, A. E.; Madalena, M.; Freitas, A.; Pereira, M. F. R.; Figueiredo, J. L. The effects of different activated carbon supports and support modifications on the properties of Pt/AC catalysts. Carbon 2001, $39,175-185$.

(7) Fraga, M. A.; Jordão, E.; Mendes, M. J.; Freitas, M. M. A.; Faria, J. L.; Figueiredo, J. L. Properties of carbon-supported platinum catalysts: Role of carbon surface sites. J. Catal. 2002, 209, 355-364.

(8) Job, N.; Pereira, M. F. R.; Lambert, S.; Cabiac, A.; Delahay, G.; Colomer, J. F.; Marien, J.; Figueiredo, J. L.; Pirard, J. P. Highly dispersed platinum catalysts prepared by impregnation of texture-tailored carbon xerogels. J. Catal. 2006, 240, 160-171.

(9) Aksoylu, A. E.; Faria, J. L.; Pereira, M. F. R.; Figueiredo, J. L.; Serp, P.; Hierso, J. C.; Feurer, R.; Kihn, Y.; Kalck, P. Highly dispersed activated carbon supported platinum catalysts prepared by OMCVD: a comparison with wet impregnated catalysts. Appl. Catal., A 2003, 243, 357365.

(10) Vergunst, T.; Linders, M. J. G.; Kapteijn, F.; Moulijn, J. A. Carbonbased monolithic structures. Catal. Rev. 2001, 43, 291-314.

(11) Crezee, E.; Barendregt, A.; Kapteijn, F.; Moulijn, J. A. Carbon coated monolithic catalysts in the selective oxidation of cyclohexanone. Catal. Today 2001, 69, 283-290.

(12) De Lathouder, K. M.; Lozano-Castelló, D.; Linares-Solano, A.; Kapteijn, F.; Moulijn, J. A. Carbon coated monoliths as support material for a lactase from Aspergillus oryzae: Characterization and design of the carbon carriers. Carbon 2006, 44, 3053-3063.

(13) Weiss, D. The catalytic properties of amorphous carbon. Proc. 5th Conf. Carbon; 1962; Vol. 1, pp 65-72.

(14) Pereira, M. F. R.; Órfão, J. J. M.; Figueiredo, J. L. Oxidative dehydrogenation of ethylbenzene on activated carbon catalysts. I. Influence of surface chemical groups. Appl. Catal., A 1999, 184, 153-160.

(15) Moreno-Castilla, C.; Carrasco-Marin, F.; Parejo-Perez, C.; Ramon, M. V. L. Dehydration of methanol to dimethyl ether catalyzed by oxidized activated carbons with varying surface acidic character. Carbon 2001, 39, 869-875.

(16) Leon y Leon, C.; Radovic, L. R. Interfacial chemistry and electrochemistry of carbon surfaces. In Chemistry and Physics of Carbon; Thrower, P. A., Ed.; Marcel Dekker: New York, 1994; Vol. 24, pp $213-$ 310.

(17) Zawadzki, J. Infrared spectroscopy in surface chemistry of carbons. In Chemistry and Physics of Carbon; Thrower, P. A., Ed.; Marcel Dekker: New York, 1988; Vol. 21, pp 147-386. 
(18) Boehm, H. P. Surface oxides on carbon and their analysis: a critical assessment. Carbon 2002, 40, 145-149.

(19) Boehm, H. P. Surface oxides on carbon. High Temp.-High Pressures 1990, 22, 275-288.

(20) Calo, J. M.; Hall, P. J. Applications of energetic distributions of oxygen surface complexes to carbon and char reactivity and characterization. In Fundamental Issues in the Control of Carbon Gasification Reactivity Lahaye, J., Ehrburger, P., Eds.; Kluwer Academic Publishers: Dordrecht, The Netherlands, 1991; pp 329-368.

(21) Zielke, U.; Huttinger, K. J.; Hoffman, W. P. Surface-oxidized carbon fibers. 1. Surface structure and chemistry. Carbon 1996, 34, 983-998.

(22) Otake, Y.; Jenkins, R. G. Characterization of oxygen-containing surface complexes created on a microporous carbon by air and nitric-acid treatment. Carbon 1993, 31, 109-121.

(23) Vinke, P.; Vandereijk, M.; Verbree, M.; Voskamp, A. F.; Vanbekkum, H. Modification of the surfaces of a gas-activated carbon and a chemically activated carbon with nitric-acid, hypochlorite, and ammonia. Carbon 1994, 32, 675-686.

(24) Haydar, S.; Moreno-Castilla, C.; Ferro-Garcia, M. A.; CarrascoMarin, F.; Rivera-Utrilla, J.; Perrard, A.; Joly, J. P. Regularities in the temperature-programmed desorption spectra of $\mathrm{CO}_{2}$ and $\mathrm{CO}$ from activated carbons. Carbon 2000, 38, 1297-1308.

(25) Hall, P. J.; Calo, J. M.; Lilly, W. D. The energetic heterogeneity of coal char surfaces: effects of heating rate on TPD spectra. In Proceedings of the International Conference on Carbon, Carbon' 88; McEnaney, B., Mays, T. J., Eds.; IOP Publishing Co.: Bristol, U.K., 1988; pp 77-79.

(26) Moreno-Castilla, C.; Carrasco-Marin, F.; Mueden, A. The creation of acid carbon surfaces by treatment with $\left(\mathrm{NH}_{4}\right)_{2} \mathrm{~S}_{2} \mathrm{O}_{8}$. Carbon 1997, 35 , $1619-1626$

(27) Surygala, J.; Wandas, R.; Sliwka, E. Oxygen elimination in the process of noncatalytic liquefaction of brown coal. Fuel 1993, 72, 409411. 